\title{
The Complexity of Determining
}

Refugeehood: A Multidisciplinary Analysis

of the Decision-making Process of the Canadian Immigration and Refugee Board*

\author{
CÉCILE ROUSSEAU, 1 FRANCCOIS CRÉPEAU, 2 \\ PATRICIA FOXEN, 3 'FRANCE' HOULE 2 \\ ${ }^{1}$ Department of Psychiatry, McGill University; ${ }^{2}$ Faculty of Law, University of Montreal; \\ ${ }^{3}$ Department of Anthropology, Mc Gill University
}

\begin{abstract}
Refugee determination is one of the most complex adjudication functions in industrialized societies. In Canada, despite a relatively broad recognition rate and a teleological interpretation of the international refugee definition, dissatisfaction with the decision-making process at the Immigration and Refugee Board (IRB) has been expressed by numerous actors. This paper documents the influence of legal, psychological and cultural factors on the process of refugee determination. Forty problematic cases referred to the research team by professionals were studied using both quantitative and qualitative approaches. The results indicate numerous problems affecting the role and behaviour of all actors: difficulties in evaluating evidence, assessing credibility, and conducting hearings; problems in coping with vicarious traumatization and uncontrolled emotional reactions; poor knowledge of the political context, false representations of war, and cultural misunderstandings or insensitivity. In a majority of cases, these legal, psychological and cultural dimensions interact together, often impacting negatively upon Board Members' ability to evaluate credibility and upon the overall conduct of hearings. These findings suggest that the refugee determination process might benefit from revised selection criteria for Board Members and refugee claim officers, as well as improved training and support for all actors.
\end{abstract}

Deciding upon refugee claims is a very complex and difficult task. According to Peter Showler, Chair of the Canadian Immigration and Refugee Board (2000), it is the single most complex adjudication function in contemporary Western societies. This complexity stems from the need for the decision-maker to have a sufficient knowledge of the cultural, social and political environment

\footnotetext{
*A preliminary version of this article appeared, in French, under the title 'Analyse multidisciplinaire du processus décisionnel de la CISR', in Refuge, Canada's Periodical on Refugees, 19(4): $62-75$.
} 
of the country of origin, a capacity to bear the psychological weight of hearings where victims recount horror stories, and of consequent decisions which may prove fatal, and an ability to deal with legal issues such as the subtle international definition of the refugee or the procedures of quasi-judicial hearings involving various pieces of evidence.

Since the mid-1980s, Western States have faced a considerable rise in the number of asylum claims, and the refugee issue has been a recurrent and highly sensitive theme in the media and on the political scene. In order to implement their international obligations under the 1951 Geneva Convention relating to the Status of Refugees and other international human rights instruments, as well as their own constitutional obligations (right to life and security of the person, protection against torture or cruel, inhuman or degrading treatment, right to equality), these States have modified the refugee status determination systems they had adopted for the Eastern European refugees fleeing Cold War communism. They have also set up institutional and procedural arrangements to treat the increased influx of refugee and asylum claims, although such arrangements are often proscribed by the particular interests of nation-states (Loescher 1993; Silk 1986). In many countries, the State institution responsible for the decision, in first instance or on appeal, is an administrative tribunal.

Canada created the Immigration and Refugee Board (IRB) in 1989 by amending the 1985 Immigration Act (c. I-2), after the Supreme Court of Canada (Singh v. Canada, [1985] 1 S.C.R. 177) had declared the previous procedure unconstitutional due to the absence of a meaningful hearing on the merits. In particular, it introduced an administrative procedure whereby decision-makers have the duty to act in a quasi-judicial manner. Since the latter decide issues of vital importance to claimants for refugee status, the legislator devised a process where claimants would be entitled to a full hearing by the Refugee Determination Division (RDD). Claimants have to prove that they have good grounds to claim refugee status. The standard of proof is somewhat lower than that of the balance of probabilities in that 'there need not be more than a 50 per cent chance (i.e., a probability), and on the other hand that there must be more than a minimal possibility' of persecution (Adjei v. Canada [1989] 7 Imm. L.R. 169 at 173).

Claimants present their case orally in front of the Refugee Division, which has sole and exclusive jurisdiction to hear and determine all questions of law and fact, including questions of jurisdiction (1985 Immigration Act, art. 67(1)). Two Board Members of the RDD assisted by a Refugee Claim Officer (RCO) hear the claimants. The RCO is not a representative of the Minister, and the latter is not normally represented unless the case involves an exclusion or a cessation of refugee status, or is of particular interest. The proceedings of the RDD are meant to be non-adversarial, another reason why the Minister is not generally represented and a 'contrary case' is not argued. More often than not, the main task of Board Members at the end of the process revolves around assessing the credibility of oral testimonies and of documentary evidence. 
The IRB consists of independent members appointed by the Cabinet (1985 Immigration Act, art. 57(2)) after a screening by a committee which makes recommendations to the Cabinet based on very general criteria which are not particularly meaningful: many appointees lack experience in immigration or refugee issues. ${ }^{1}$ This absence of specific criteria for the selection of Board Members is a major lacuna in the 1989 system. Despite the important training programme developed by the IRB, many actors in the system (lawyers, NGOs, civil servants, communities, etc.) have signalled, over the past eleven years, numerous instances where the legitimacy of the IRB decision was dubious, for reasons related to the competence of the Board Members and other actors.

Several reports contain recommendations aimed at correcting the difficulties encountered by the IRB in exercising its mandate. The Hathaway Report (Hathaway 1993) dealt with problematic relationships between Board Members, as well as a range of systemic weaknesses. The Crépeau-Houle Report ${ }^{2}$ specifically made suggestions concerning the selection and training of Board Members, as well as the independence of the tribunal. The Réseau d'intervention auprès des personnes ayant subi la violence organisée (RIVO), in the name of the Canadian Network for the Health of Survivors of Torture and Organized Violence (CanNet), has prepared a Code of procedure and ethics for the treatment of victims of torture or severely traumatized persons (see http://www.cam.org/ rivo/RIVO99.html), which the IRB is presently helping to review. Some authors, in addition, have pointed to the need for better cultural communication and sensitivity on the part of IRB Members (Barsky 1994, 2000; Pelosi 1996).

Concurrently, international quasi-judicial decisions also point to the difficulty of the refugee determination task. For example, the United Nations Committee against Torture has set stringent criteria that testify to the complexity of such decision-making. Its cases involve the evaluation necessary to decide whether an alien will be deported to his or her country of origin despite a claim that he or she may be at risk of torture, and the Committee has outlined several skills required of decision-makers: very accurate and specific knowledge of the political and social situation in the country of origin (Communication no 120/1998: Australia. 25/05/99. CAT/C/22/D/120/1998) and the ability to understand and evaluate the psychological aspects of the process (Communication no 101/1997: Sweden. 16/12/98. CAT/C/21/D/101/ 1997).

In addition, the United Nations High Commissioner for Refugees has suggested that similar criteria be used by States when determining refugee status:

It should be recalled that an applicant for refugee status is normally in a particularly vulnerable situation. He finds himself in an alien environment and may experience serious difficulties, technical and psychological, in submitting his case to the authorities of a foreign country, often in a language not his own. His application should therefore be examined within the framework of specially established procedures by qualified personnel having the necessary knowledge 
and experience, and an understanding of an applicant's particular difficulties and needs (UNHCR 1992: par. 190).

These national reports and the international case law and soft law suggest that a thorough examination of the refugee determination process should be undertaken through the lens of various disciplines and should include a multidisciplinary analysis which takes into account the legal, cultural and psychological dimensions of the process. However, there has been no comprehensive multidisciplinary study on the decision-making process to date, and the absence of precedent in the literature highlights the need to devise the appropriate analytical tool for such study.

The general objective of this research project, therefore, was to identify the nature and cause of the discrepancies in appreciation of many cases, between independent decision-makers and impartial specialists (such as the Board Members or the RCO) on the one hand, and professional experts in particular fields (such as lawyers, doctors and psychologists) on the other. More specifically, we wanted to analyse the decision-making process by focusing on the cultural, psychological and legal factors that influence the various actors, and to suggest effective solutions that go beyond the haphazard fixing that is often applied when some embarrassing piece of news finds its way into the media.

This paper describes the methodological approach taken in creating the intellectual tools for the analysis, as well as the results obtained through their use in analysing some forty cases decided by the IRB in Montreal.

\section{Literature Review}

\section{Legal Literature}

The literature considered here consists essentially of a general review of the case law that emanates from the Federal Court of Canada. This review does not purport to be exhaustive and is limited to the cases that are pertinent to the analysis of the decision-making process.

The Federal Court of Canada has exclusive jurisdiction to review the legality of refugee determinations. Therefore, the function of the Court is to set the legal parameters to be followed by the IRB when it makes decisions. For reasons which are possibly linked to the lack of competence of Board Members, these legal guidelines appear, at times, not to be followed. This results in negative decisions which are often not well-founded and constitute, by this very fact, a breach of the fundamental right to security of the person of the refugee claimants concerned (Article 7, Canadian Charter of Rights and Freedoms).

Board Members can experience difficulties in evaluating evidence, and this often leads to erroneous findings of facts, unreasonable conclusions or a failure to give proper weight to evidence introduced during the course of the proceedings. The Trial Division of the Federal Court can review these errors when 
judges are of the opinion that the Members did not weigh the evidence properly or mis-stated, misunderstood and misconstrued the evidence presented at the hearing (Bouguettaya 2000).

It is entirely open to the IRB to base its decision on documentary evidence rather than testimonial evidence provided it has good reasons to do so after properly weighing the probative value of all the evidence presented at the hearing (Menaker 1997). However, when the Board does not have any documentary evidence before it with respect to a central fact of the claim and there is any adverse credibility finding with respect to the applicant, the Board should assess the testimony (Vidhani 1995). Normally, the Board should grant the applicant the benefit of the doubt in cases where documentary evidence is lacking (Chan 1995). Yet, rejections are often based on the lack of credibility of the claimant on the basis that the story is 'implausible' (Leung 1994), but the reasons are unconvincing, if not merely speculative (Njoko 1995).

Finally, expert evidence has to be handled carefully by Board Members. They cannot comment negatively on applicants' demeanour, make remarks on their emotional response to their counsel's questioning and determine that they are evasive, incoherent and disjointed in their testimony, if there is a medical report explaining the applicant's behaviour. Specifically, psychiatrists will often conclude that the applicant's 'manner of reporting his history and his emotional reactions while reporting it were consistent with the history which he provided' (Zapata 1994). It is not open to the Board to disregard expert evidence without indicating its reasons in the decision, especially when it explains the applicant's demeanour, which led to a finding of lack of credibility (Sivayoganathan 1994).

In addition to problems in assessing evidence, Board Members may also demonstrate difficulties in conducting a hearing. The statute imposes a duty on the Board Members to conduct hearings informally and expeditiously. However, in doing so, they have to remain fair towards claimants, especially since procedural safeguards associated with the right to be heard are guaranteed to claimants. With these provisions, it should be clear that considerations of fairness should prevail over those of expeditiousness. In practice, however, this objective is often contradicted by the inquisitorial zeal of RCOs and Board Members.

As a neutral agent, the RCO's role is to bring all the relevant elements of the case to the attention of the Members of the Refugee Division and to communicate the case to the claimants before the hearing so that they will not be taken by surprise. Members can also ask the claimants questions, but they have to be more careful than RCOs in order not to 'cross the line' and appear to be partial. RCOs and Board Members can clarify inconsistencies, falsehoods, confusion or mistakes, but the line of questioning has to end when questions become unfair, harassing or sexist (Yusuf 1991). Despite the degree of discretion granted to the Board in assessing credibility, the Board has an obligation to express any negative findings of credibility in clear and unmistakable terms (Parizi 1994). 
The primary function of the IRB is to weigh and assess the evidence before it. Although there is no obligation of the Board to discuss every piece of evidence, it is required to address those pieces which contradict the Board's finding on key issues (Gengeswaran 1999). Otherwise, the Court may infer that the tribunal made an erroneous finding of fact without regard to the evidence (Otoo 1996). What is required is that the Board's reasons demonstrate an understanding of the pertinent issues and of the relevant evidence (Magana 1996). The simple statement that the tribunal had reached its decision 'after careful consideration of all the evidence adduced at the hearing' is not sufficient when the decision makes little or no reference to the principal bases of the applicant's claim (Alfred 1994).

In addition, Board Members must not give the impression, in their reasons for decision, that they made a painstaking analysis of the transcripts to find contradictions (Gracielome 1989). Where the Court feels that the Board has overreached itself in its search for inconsistencies, the Board's decision can be set aside (Owusu-Ansah 1989).

\section{Psychological Literature}

In terms of the psychological factors, two distinct phenomena deserve particular attention: the influence of traumatic experiences on claimants' testimony and the impact of their stories on the various professionals involved in the legal process.

A very significant number of refugee claimants' accounts include instances of torture, rape, arbitrary detentions, threats, and armed attacks (Fornazzari 1995; Silove et al. 2000). These events can engender post-traumatic psychological reactions in the claimants, which often affect both their ability to testify and the content of their testimony. Being forced to recall the traumatic events can trigger powerful avoidance reactions, either conscious or unconscious. These reactions protect the person from retraumatization and the social stigma associated in some cultures with being a victim or with certain specific traumas, sexual violence in particular (Atlani and Rousseau 2000). In some cases, the claimant can be overwhelmed by powerful emotions of anxiety, sadness, and anger leading to temporary loss of control or to dissociation. For people who have suffered torture, the court setting can also evoke interrogation conditions and provoke a panic reaction (Rousseau 2000).

In most cases, however, awareness of the importance of the court decision leads the claimants to mobilize all their resources, so the influence of traumatic experience on their testimony will be more subtle. The literature indicates that trauma can alter the account of an experience in a number of ways. First, it alters perception of time and distorts reports of the time sequence (Terr 1983). Pynoos and Nader (1989) observe that it can also distort spatial perception: people who have had extreme exposure tend to consider retrospectively that they were safer than they were, while more distant observers will describe 
themselves as directly exposed to the trauma. Memory blocks and a wide range of dissociative phenomena also compromise the coherence of trauma stories (Kirmayer 1996). Finally, difficulty in concentrating is responsible for numerous little mistakes which are easily interpreted as lack of credibility in a legal setting. Because of all these interrelated factors, trauma stories can be very difficult for non-specialists to interpret and psychological or psychiatric expertise may play a key role in trying to disentangle the effects of trauma from credibility issues (Levy et al. 1998).

The recounting of traumatic events also indirectly transmits trauma from the claimant to the decision maker or to other professionals involved in the decision-making process. Board Members in particular are subject to major psychological stress due in part to the severity of the traumatic accounts they have to listen to, and in part to the psychological weight of the decisions they must render, some of which can have quite dramatic repercussions on the safety of the refugee claimant. In Canada, most Board Members listen to two claimants' stories each day of the week, for three consecutive weeks, and then have a week without hearings to write their decisions. Studies of war-time trauma in the wake of World War II and the Vietnam War brought to light the fact that war does not only affect those who experience it directly, but also has repercussions on the close social relationships and networks that a person may be involved in (Danieli 1998; Rousseau 1998). The indirect transfer of trauma through verbal accounts has been particularly well documented in therapists who have treated traumatized patients and is known as 'vicarious traumatization' (Watson 1995). In the therapeutic setting, it is the therapists' empathy for the victims that makes them vulnerable, for they cannot use the usual defences of avoidance or denial to protect themselves from the images associated with the story that has been told (Peltzer 1997).

Vicarious traumatization can provoke the development of typical symptoms of post-traumatic stress disorder in exposed individuals (nightmares, flashbacks, startle reactions, avoidance, denial, uncontrolled emotional reactions). Psychodynamic analyses have also demonstrated how traumatic histories can evoke voyeuristic and sadistic impulses in the listener (Vinar and Vinar 1989). Overexposure to these types of accounts often triggers defensive reactions that lead to trivialization of horror, cynicism, and lack of empathy.

Intensive exposure to traumatic stories can also be responsible for more systemic effects, and in particular, for conflicts and disagreements at the institutional level. These confrontations reflect a splitting process where the 'evil' has to be distanced as much as possible from oneself (Jaranson 1995; Moeller and Christiansen 1996). Projection defences involved in the split can result in dismissal or demonization of the 'other', a mechanism which can prove particularly harmful in a court situation. In spite of increasing evidence of the significance of vicarious traumatization phenomena, they have never been studied in the immigration court setting, but it can be hypothesized that they are likely to have a major influence, both at the personal and the institutional level, in the decision-making process. 


\section{Cultural Literature}

In line with the large numbers of immigrants and refugees arriving in Europe and North America over the past two decades, there is a growing academic and policy literature on cultural processes such as acculturation, adaptation and multiculturalism (and their applications in such fields as health, education, communications and marketing). Many authors have moved beyond traditional unilinear notions of adaptation and acculturation; some, for example, have shown that situations of marginality, alienation and poverty in the host culture impact negatively on refugee well-being more than actual experiences of violence and torture in the home country (Beiser 1993).

Research in the disciplines of anthropology and intercultural communication, in addition, has offered much evidence that communication between people from different cultural backgrounds can lead to radical misunderstandings (Geertz 1973; Knapp et al. 1987; Samovar and Porter 1994). Different cultural frameworks - which encompass beliefs, attitudes, motives, practices, world views, as well as notions of time, spatial orientation, causality, truth, social hierarchy and ways of narrating - frame the ways in which people perceive, experience and interpret their social and personal realities, as well as the meanings and significance they assign to everyday occurrences and commonplace understandings. As much research has shown, when people do not share the same cultural references, rules and codes-information that is largely internalized and communicated unconsciously - numerous communication failures occur, ranging from misinterpretations about minute non-verbal cues to different assumptions concerning the essential meaning of concepts (Goffman 1969); moreover, such cultural misunderstandings can lead to feelings of hostility and biased judgements (Aigner 1995).

Much academic attention has also been paid to the institutional processes through which refugee identity is structured and normalized, and to the power relations, discourses and ideologies shaping the experience of refugees worldwide (Zolberg et al. 1989; Malkki 1992; Daniel and Knudsen 1995). Some of this scholarship points to the political construction of 'refugee identity', which is framed by international institutions within a discourse emphasizing the victimhood, suffering, and pathology of refugees, and is itself related to the Western discourse on rights and charity (Malkki 1992). In the context of Western host societies in particular, a discourse separating 'deserving' refugees from those deemed to be 'undeserving' or 'false' governs and restricts the acceptance of refugees. Indeed, some authors argue that the juxtaposition of the concept of a 'right' to refuge or asylum with the fear of uncontrolled immigration has led to popular and institutional negative characterizations of refugees as 'queue jumpers', cheats or economic immigrants (Pelosi 1996; Silove et al. 2000). Others have argued that within contexts of terror, escape and asylum-seeking, a profound sense of mistrust governs both refugee perceptions of authorities and the way refugees are in turn perceived by authorities and institutional actors in both home and host contexts (Daniel and Knudsen 1995). 
Despite the broadening literature on refugees, immigrants, and inter-cultural communication, there exists a relative dearth of information regarding the impact of cultural difference and communication in the refugee determination process itself, or, indeed, within the field of refugee and immigration law in general. Given the critical decisions that are made in refugee hearings, the issue of intercultural misunderstanding is of extreme importance. Such hearings involve the intersection of radically different cultures, assumptions, belief systems and reference points in a highly charged, intense and short-term setting. Refugee claimants are required to prove their claims, which usually involve complex political situations and personal decisions as well as cases of extreme brutality, in a context where they may not be understood, and often with little documentation. As such, small and large cultural misunderstandings can have devastating impacts on hearing outcomes and the lives of those who flee persecution. Kälin (1986) has outlined particular obstacles to the interaction between asylum-seekers and officials, including: a) the manner in which asylum-seekers express themselves; b) the interpreter; c) the cultural relativity of notions and concepts; d) different perceptions of time; and e) the cultural relativity of the concepts of 'lie' and 'truth'. Barsky (1994) has argued that the refugee hearing often becomes a test of the claimant's ability to construct an appropriate image of the 'convention refugee'- that is, to satisfy the expectations of the decision-makers, which themselves are based within particular political, economic, cultural and moral discourses. As a result, claimants who are most able to navigate and understand the expectations of the host country tend to produce a successful 'refugee' image, while others whose narrative style and retelling of events do not fit into such expectations may be misunderstood and rejected.

Two noteworthy studies have examined these processes in refugee hearings at the IRB in Canada, both pointing to some serious difficulties engendered by intercultural miscommunication in this context. Barsky (1994) has looked at how the social discourse surrounding refugees is reproduced and normalized in hearings and throughout the refugee determination process; he illustrates how unstated power differentials and hierarchies interact with cultural assumptions in the production (or rejection) of the refugee 'Other'. Following his lead, Pelosi (1996) points to some common, albeit subtle, pitfalls of intercultural communication and the negative impact of ineffective communication on the outcome of refugee hearings. First, she argues, a claimant's vulnerable state of mind during the hearing may lead to emotional reactions or signs of distress that are misinterpreted by the decision makers. Psychological fragility is often caused or reinforced by the intimidating surroundings of the hearing, by culture shock and bewilderment regarding unfamiliar signs and symbols, by fear of the hearing's outcome or of being misunderstood, or by psychological symptoms caused by trauma, which might range from nervous laughter to a blank and indifferent affect. Such anxiety is often expressed through cultural idioms unfamiliar to the decision-maker, can result in hesitance or contradiction, and may be interpreted as a lack of credibility. 
Both Barsky and Pelosi show how the institutional culture of the IRB itself, prescribed within a particular socio-political context and subject to specific world views, codes of behaviour, social standards and professional norms, is limited by its own cultural notions and frameworks for ascribing meaning. As such, the aims of neutrality and objectivity are themselves cultural constructs which, ironically, are severely compromised by the numerous errors of cultural interpretation occurring at various levels within refugee hearings. These misunderstandings - which can determine a person's fate-occur at a subtle, seemingly invisible level, often leaving the actors oblivious to the cultural processes leading to such clashes.

\section{Method}

\section{Research Protocol and Sample}

The protocol reflects the primary objective, that is, to determine and describe the legal, psychological, and cultural factors associated with lack of consensus on cases of refugee claimants heard by the Immigration and Refugee Board (IRB). It is a cross-sectional retrospective study. The approach is qualitative, with in-depth study of a selected number of cases, definition of appropriate categories in the legal, cultural, and psychological fields, and application of those categories to all the available cases.

The initial sample was to be a selection of cases from three sources: lawyers, health professionals and NGOs, and the IRB. When the IRB refused to take part, the cases were taken from the first two sources using a snowball sampling method. There were three criteria for inclusion: (1) The application for refugee status was refused; (2) There was a major disagreement between at least two of the actors (IRB, lawyers, health professionals and NGO) about the decision; (3) The persons referring the cases had noted major legal, psychological, or cultural problems in the case. Cases handled prior to 1994 and those for which documentation was insufficient for in-depth analysis were excluded.

Eighty-four cases were referred to us by lawyers (60 per cent) and health and community workers (40 per cent). Forty-four cases had to be excluded on the basis of the criteria listed above or because consent could not be obtained from the claimant (impossible to find, deported, etc.). Only four claimants refused their consent; four others never returned our calls, and so we considered them to have refused, which left us with a refusal rate of 17 per cent.

Data were gathered between June 1999 and May 2000. Members of the fieldwork team went all over Montreal to obtain the various documents, which were then sorted and reviewed to ensure the anonymity of those concerned.

\section{Definition of Variables}

First, focus groups consisting of researchers and actors from the different settings helped establish the characteristic factors likely to explain divergences in the 
perceptions and evaluations of the various actors involved in the hearing process. The list was validated and completed when we conducted our qualitative analysis. We divided the factors into three categories, described below.

\section{Legal factors:}

- For all actors, problems working within the framework of a procedure that is by its nature inquisitory.

- For Board Members and RCOs, problems assessing the relevance (expert evidence, documentary evidence, etc.) and the weight of the evidence (significance of contradictions between claimant's personal information form (PIF) and oral testimony; use of judicial notice; understanding of the social and political situation in claimant's homeland, etc.).

- For Board Members, problems in conducting a hearing (questioning claimants, respecting code of ethics and legal etiquette, etc.).

- For Board Members, problems in writing the reasons for decision.

- For claimants' lawyers, lack of preparation for the hearing.

- For interpreters, problems in correctly translating claimants' testimony, due to intercultural barriers, such as dialect, verbal and non-verbal behaviour, etc.

\section{Psychological factors:}

- For all actors, but especially Board Members and RCOs, problems coping with transmission of trauma, such as:

- Strong avoidance reactions (direct avoidance, denial, and normalization of extreme situations, sometimes expressed as cynicism, etc.).

- Uncontrolled emotional reactions in confronting traumatic experiences (anger, victims perceived as aggressors, lack of empathy, reaction formation, etc.).

- Lack of knowledge of psychological consequences of trauma (symptoms and short-, medium-, and long-term effects, relationship between victim and torturer, etc.).

- Improper use of expert reports prepared by physicians and psychologists (prejudice or ignorance, status of expert, tendency to take place of expert, etc.).

- For claimants' lawyers, tendency not to protect claimants from being retraumatized.

- For health professionals, lack of clarity of medical and psychological reports presented.

\section{Cultural factors:}

- For all actors, but especially Board Members and RCOs:

- Lack of familiarity with the political and social situation in claimant's homeland. 
- Misrepresentations of daily life in a country racked by war or other conflict.

- Simplistic representations of social coherence (stereotypes).

- Cultural misunderstandings, insensitivity and prejudice based on sex, ethnic origin, religion, and sexual orientation.

- Incomprehension of problems with time sequence and narrative coherence in accounts of war and flight.

\section{Analysis}

The analysis had three parts:

- Development of a checklist used to classify cases by socio-demographic profile, reasons for and source of referral, and available documents;

- In-depth analysis of ten cases to refine and complement the determination and description of the factors under study;

- Development of an analysis grid based on the factors that could be applied to all the cases to obtain a quantitative picture of the significance of the interrelationships between the factors.

The case files included the IRB decision, the personal information form (PIF) filled in by the claimant on arrival, the documentary evidence, the judicial review application after initial refusal, medical and psychological expert reports, affidavits, identity papers, and various other documents. The complete recordings (on cassettes) of the hearings were obtained for all cases studied in depth and for a number of others, as well.

Most of the cases examined (87.5 per cent) were of claimants who arrived between 1995 and 1998. Hearings lasted anywhere from less than an hour (2.5 per cent) to more than half a day ( 25 per cent). Seventy per cent of claimants had only one hearing, 20 per cent had two, and 10 per cent had three or four. Compilation of the checklists enabled us to draw up a socio-demographic profile of our sample. Of particular interest is the fact that 75 per cent of claimants were between the ages of 25 and 44 and that men and women were equally represented. Most (57.5 per cent) were from Africa, while 20 per cent were from Latin America, and 20 per cent from Asia.

To select the ten cases for in-depth analysis, we used several criteria to build up a diversified sample in terms of homelands that posed a risk to personal safety (Congo, Cameroon, Burma, India, Mexico, Kazakhstan, Honduras), sex, age, sexual orientation, and family situation.

Each of the selected cases was analysed from three points of view, by legal, cultural, and psychological professionals with extensive knowledge of the issues and experience in content analysis in their respective fields.

Another team of qualified professionals did the quantitative coding of all the cases after the categories were confirmed in each of the three areas. 


\section{Findings}

\section{Qualitative Findings}

Legal Findings: In the last decade, the Federal Court laid down the general principles which must guide the IRB in the decision-making process. However, our research showed that very obvious mistakes in the handling of evidence are still being made and that hearings can still be poorly conducted, both situations often resulting in reasons for decision which are clearly inadequate.

Board Members often conclude that the claimant's story is not credible when they find contradictions between the notes taken by an immigration officer at the point of entry into Canada, the PIF completed by the claimant, and the latter's oral testimony during the hearing. However, in several cases, the 'contradictions' were either minimal, or had been explained at the hearing, or could have been explained had the Board Members asked the appropriate questions. For example, in one case, the claimant explained in oral testimony that the person she was living with was the leader of a cultural group, and that this information was not transcribed in her PIF due either to a confusion on the part of the lawyer or to a bad translation. The panel refused this explanation since, at the beginning of the hearing, she had solemnly affirmed having full knowledge of the contents of her PIF and since the latter had been translated for her.

Evaluation of the evidence from expert witnesses or reports (such as medical or foreign affairs experts) can be capricious. In one case, an expert psychological report provided details of the post-traumatic stress syndrome suffered by the claimant after he was tortured. The report included pictures taken immediately after his arrival in Canada showing his body covered with cigarette burns. A health professional had conducted six consecutive interviews of the claimant, making a thorough assessment of his condition and relating it to the details of his story. Nevertheless, the claim was rejected and the conclusions of the expert report summarily dismissed. One of the Board Members said during the hearing that he always took expert psychological reports 'with a grain of salt'. It was further discovered, during the hearing, that he had not even read the report: after repeated requests from the lawyer, the Chair had to interrupt the hearing so as to allow the Board Member to read it. In addition, the Chair herself made dubious comments about the fact that she herself was a smoker, implying that she did not give much weight to the cigarette burn marks or to the expert report. These actions show a serious lack of appreciation as to the precise reason for having an expert report and what evidentiary weight it carries.

In another case, the RCO acted as an expert on the Thematic Apperception Test (TAT) contained in an expert report. He subsequently made disdainful remarks concerning the subjectivity of psychology, and in particular, of psychoanalysis. Neither the Board Members, nor the RCO took the expert status of the psychologist concerned seriously and they declared that the report and the testimony were not credible overall, without any further explanation. 
In a case from Kazakhstan, the claimant had not mentioned in the PIF that her young son had been burned by a Molotov cocktail thrown at their house. During the hearing, she explained that she did not want him to be interrogated, because she wanted to protect him from further suffering. A psychological report presented in evidence revealed the parents' feelings of despair and powerlessness with regard to their son's injuries. The mother also had symptoms of trauma and wanted to protect her son at all costs from being exposed to stimuli capable of triggering additional trauma. The Board Members determined that the claim was not credible based on two omissions, including the fact that the attack on the son was not revealed. This showed a lack of appreciation of the value of the expert report in explaining the avoidance mechanisms seen in a traumatic situation, in the context of a mother's desire to protect her son.

Many cases show little consideration for the documentary evidence provided by the counsel for the claimant, and often this evidence is not even mentioned in the reasoning for rejection of the claim. For example, the members affirmed in one decision that the documentary evidence in no way showed that the claimant's minority group was oppressed, a statement that blatantly and without explanation contradicted documentation provided to the panel.

Board Members also show discomfort in a non-adversarial setting such as the refugee determination process. For example, at the beginning of the hearing of one particular case, the Chair declared from the outset that she did not want to hear the claimant's story as she suspected that he would tell the same story as she had already read in the PIF. She rejected the counsel's request for permission to ask the claimant to clarify various points, and asked the RCO to proceed with her questions. This demonstrates a serious misunderstanding of the role of a hearing in any adjudicative process, which is to allow the matter to be adequately and fully addressed. In several other cases, the Board Members and the RCO argued with the counsel or the claimant, the discussion often becoming heated, an indication of uncontrolled interpersonal conflict. In other cases, Board Members showed outright disbelief of the claimant's story, made inappropriate comments or displayed cynicism. All these patterns of behaviour indicate a lack of appreciation for judicial decorum and etiquette, which should be respected by the members of an administrative tribunal, since these rules exist to ensure that justice is done in a dispassionate manner.

In addition to the conduct of Board Members during hearings, the written decisions often show serious flaws, either by containing only a list of contradictions between the PIF and the oral testimony, or by simply declaring laconically that the claimant is not credible, or by not even mentioning the evidence presented, especially documentary evidence. In one case, the decision starts with a declaration stating that the claimant's testimony was very vague and lacked precision: on the contrary, taped recordings of the hearing show that the testimony was clear, articulate, precise, and that the claimant answered all questions calmly and thoroughly. 
In a case from Congo, the hearing focused on events occurring after the rape of the claimant by the military, which was the central event forming the basis of the refugee claim. The question of rape was not addressed during the hearing. The rejection of the claim was based on minor aspects, such as contradictions between the PIF and the oral testimony regarding the question of when exactly the claimant had become conscious of the presence of her brother-in-law in the vehicle that provided her escape. This 'contradiction' was sufficient on its own, in the eyes of the Board Members, not only to reject the claim, but also to conclude that the claim had no credible basis (a finding that prohibits any review of the decision). The Board Members addressed some but not all of the issues arising from the rape, even though they were fundamental elements of the claim. They did not, for example, include the existence of a medical certificate in their deliberation.

In a case from Burma, interrogation of the claimant lasted five hours and was conducted in a disorderly manner. There were constant repetitions of questions to which the claimant had already given satisfactory answers. The repetitions were not justified by the Board Members and were evidence of a confrontational attitude that bordered on harassment. Generally speaking, such repetitions and revisiting of questions creates a tense atmosphere and gives the impression that the Board Members do not believe the claimant. However, it is impossible to identify precisely which facts or events Members find lacking credibility. In fact, this decision demonstrated that the members did not quite know on which grounds to base an appropriate challenge of the claimant. This case revealed a serious lack of preliminary preparation that can be felt throughout the hearing.

In sum, the review of the cases noted above demonstrates that some Board Members fail to carry out their duties effectively. They do not always know how to treat expert evidence, or they use it in ways which are clearly inappropriate. They tend to create an atmosphere in the hearing room that is not conducive to good decision-making. They have also demonstrated difficulty in conducting a hearing correctly. Such basic rules of evidence and procedure are, however, of obvious importance for a tribunal that makes daily decisions concerning people's life, liberty and security.

Psychological Findings: Qualitative data analysis from a psychological perspective suggests major problems in two areas: knowledge, and capacity to transmit knowledge, about the impact of traumatic experiences and the effect of recounting them; and the difficulty of all concerned in coping with vicarious traumatization.

Lack of knowledge of the impact of traumatic experiences is particularly obvious among Board Members and RCOs. Frequently, typical post-traumatic symptoms are misinterpreted as signs that the claimant's story is not credible. Omissions of an event like rape from the PIF are commonly considered to be evidence that it probably did not happen, a judgement that ignores the personal and social consequences of such disclosure. In the case of the young Congolese woman, the Board Members could not understand her non-disclosure of rape 
at the border and on the PIF, even though her previous disclosure of this event had had devastating consequences for her: her husband had abandoned her, and her father had been assassinated because he intended to ask for her aggressors, officers of the Kabila regime, to be brought to justice. Dates and time sequences are another major source of misunderstanding. Board Members generally consider that incidents such as detention or events following a major trauma should be reported accurately. In the case of severe trauma, this is often impossible. Classical signs of trauma such as confusion and forgetting details are often met with growing impatience on the part of Board Members and RCOs. In response to this Congolese woman who was raped and could not remember the exact date, nor the date of her conversation with the medical personnel assigned by Immigration, a Board Member said, very sarcastically, 'So you don't remember ...', implying that the claimant was lying.

As previously presented in the legal findings, the Board Members often lack the skills to use medical and psychological expertise to compensate for their own lack of knowledge. On the other hand, these expert opinions can also be misleading. Analysis of the medical and psychological reports shows that therapists have a tendency to predict the claimant's behaviour during the hearing, based on the therapeutic interview. The IRB hearing, however, presents a radically different environment from the secure patient-professional relationship. Although aimed at protecting the claimant, firm statements by a doctor or psychologist can often lead to problems later, because, if the actual testimony contradicts the prediction, the expert's entire report may be called into question, thus damaging the claimant's credibility. The technical jargon used by some experts may also put off some readers, who may overlook important conclusions because they fail to understand them. Some assessments lack clarity, as the appraisal of the capacity to testify is often mingled with an appraisal of the credibility of the patient's story. Finally, sometimes conclusions are too directive and perceived as intrusive by the Board Members.

Vicarious traumatization appears to affect everyone involved in the claimant's case, but it manifests itself differently depending on the actor's role in court. Board Members and RCOs, who are not linked to the claimant (so their reactions are probably more internalized), have the most blatant avoidance reactions. These take numerous forms: direct avoidance, denial, and trivialization of extreme events.

Direct avoidance is manifested by an expressed wish not to hear the traumatic story. In the case of a young claimant from Chiapas, the chairwoman stated repeatedly that she did not want to hear a description of the torture suffered by the claimant, and that reading the PIF was sufficient evidence regarding that issue. She said: 'The details being described, torture and all that, I don't want to hear that'. The lawyer insisted that the claimant recount part of his story and she replied, 'Sir, I personally do not want to hear from him what has happened, what happened to his father or to his two sisters. I find it inhuman to ask him to repeat it [...]. Maybe he experienced it; maybe ... I don't need that'. The claim was rejected for lack of credibility. 
Direct avoidance is often presented as a way to protect the claimant, a solicitude which is then contradicted by the fact that accounts of traumatic events are either dismissed or considered not credible. In the case of the young woman from Congo, the RCO insisted: 'I've already told you that I don't want to go into details like that, madam. Especially for you ... this is not necessary. I want to know how you got out [of prison] and what happened before you got out [the rape and mistreatment happened before the claimant escaped]'.

In other cases, avoidance is more indirect and is manifested by totally ignoring traumatic events. A young Latin American homosexual had been assaulted and raped by soldiers. After he filed an official complaint with the police about the attack, he was burgled, threatened over the phone, and attacked again. After his departure for Canada, his partner was killed before he had a chance to join him. The RCO, in her oral summary of all the important facts of the case, failed to mention the murder of the partner, and scarcely a single question was asked about this essential fact. In the hearing of a Burmese woman, the Board Members emphasized factual information that was not always relevant to the case (geographic details, renewal of passports, etc.). The Board Members glossed over the subject of the arrest, rape and abuse of the claimant, her psychological and physical problems (shame, fear, the way she hides the scars), the racist harassment and insults she suffered in her country of origin. They quickly changed the topic, discussing more neutral information, such as the type of building that the claimant was kept in or the existence of a demonstration permit. Besides showing a complete lack of empathy, this treatment of the claimant was a way for the Board Members to avoid or deny her suffering and dismiss its importance.

Trivializing horrific events is another form of avoidance that often manifests itself as cynicism. As demonstrated in the case of the Mexican mentioned earlier, confronted with the claimant's multiple cigarette burns, a Board Member said, 'You know, I smoke ...'. This apparent cynicism is indicative of a traumatic situation being treated as normal. Establishing a parallel between an everyday occurrence like smoking, and torture, renders the torture innocuous.

Very commonly, confronting the claimant's traumatic experiences provokes uncontrolled emotional reactions in the other people present. Although most hearings begin on a courteous note, this often turns to anger or hostile exchanges. In the case of a claimant from Central America, soldiers assaulted him and another man, leaving the latter in what appeared to be a state of shock or a coma. The claimant asked the soldiers (who were the only ones around) for help for his companion and was brutally told to leave, which he eventually did. The dead body of the other man was discovered a few days later. In the course of the hearing, a Board Member, showing clearly that he did not believe the story, angrily asked the claimant how he could have asked for help from their torturers; five minutes later, and still angry, he asked how the claimant could have left his companion in the hands of their torturers. These responses show a very strong emotional reaction, a lack of empathy, and an association 
of the victim with the aggressor, all symptoms of an inability to cope with the emotional stress created by the hearing.

In the case of the young woman from Burma, the general tone, which was courteous at the beginning of the hearing, became progressively more charged. The Board Members even became provocative at times, repeating the claimant's words and being sarcastic. For example, a Board Member asked the claimant if she was in the habit of disobeying her parents. The members also laughed among themselves. They seemed to be creating a psychological distance from the emotional intensity of the problems experienced by the claimant, to the point where they were no longer able to listen with empathy. As a consequence of their own psychological self-protection, they first took an adversarial stance, then showed scorn for the claimant. These attitudes in turn influenced the claimant's reactions, which ranged from anxiety, demonstrated in the tone of voice and rhythm of speech, to impatience, manifested as disrespect for the rules of the hearing, and finally to total helplessness (crying).

Sarcasm can also provoke rebound anger in the claimant. In a Honduran claimant's hearing, the following dialogue occurred:

Board Member: 'Were they shooting at you because they wanted to kill you or were they shooting at you because you were trying to run away?'

Claimant: 'I was just in the middle of the plantation and I heard some shooting and I thought, that's what I think, that they try to kill us.'

Board Member (sarcastically): 'So you're not sure?'

Claimant (becoming angry): 'Do you think that they were shooting at ... at ... the plants ... at the corn plants?'

Lawyers, while often forming close alliances with their clients, can also react inappropriately to the tense atmosphere of the hearing, for example laughing about an obviously sad situation. They also have a tendency to expose their clients to retraumatization, so as to present more convincing testimony. In one case, a lawyer accepted the chairperson's suggestion that an eleven-year-old child's torso be stripped during the hearing in order to show his scars, which was totally unnecessary, since there was already a thorough medical report and pictures of the child's body in the file. The child was severely retraumatized by the event, and the actors even noticed it during the hearing. One Board Member, caught off guard, reacted by stating: 'He can just think of me as his grandmother.'

Finally, the difficult emotional climate also has repercussions on relations among the parties. Sometimes interpersonal conflicts between the actors (often between the lawyer and either the Board Members or the RCO) turn into an open fight for control and power over the hearing, to the detriment of the decision, which is put at stake by the fight.

Cultural Findings: Numerous types of cultural misunderstanding or miscommunication can be found in the cases examined. In several of these, Board 
Members and RCOs demonstrate a very poor understanding of the political complexities of violence, and of the nature of persecution where ethnic, religious, cultural and political antagonisms interact. Simplistic assumptions regarding political violence are evident in each case; the Board Members often seem to posit war as a Manichaean situation where clearly-defined groups function in opposition to or in alliance with one another, and where an individual, if truly persecuted, will immediately flee. This lack of basic knowledge concerning the political and social situation in the country of origin often contributes to their final decision.

In a case involving a Tutsi claimant from Rwanda, for example, the Board Members demonstrated a highly simplistic assessment of the genocide/postgenocide situation, and the changes wrought by ethnic violence over time. They argued that Tutsis should be safe in Rwanda since the government is Tutsi, and that the government is democratic since it released Hutu prisoners; they rejected the expert witness's testimony which outlined a more complex political situation, stating that the latter was biased. In a case from Chiapas, Mexico, a Board Member described the conflict as a clear-cut situation where landless indigenous peasants were fighting a repressive army; in consequence, he argued that the claimant's uncle, an army official, could not possibly have been able to buy land in Chiapas in 1995, saying that 'this seems to me completely out of context and unimaginable' (translated from French). In fact, much of Chiapas has been heavily militarized, with pockets of Zapatista support existing in some areas while others side with the army; that an army member would have been able to buy property at this time is perfectly plausible.

In several cases, the Board Members' concept of daily life in a country at war, in low-intensity conflict, or in situations of persecution, was simplistic or false. They seemed unable to envisage situations where localized violence reigns as conflicting groups struggle for power, or where the military or police are involved in corruption, intimidation and abuse of power. In a Kazakh case, the Board Members' lack of comprehension regarding local ethnic persecution (of the Dungan population) was clear. As one of their main arguments for rejecting the claim, the Board Members stated that, rather than being persecuted by nationalist Kazakhs due to their ethnic status, the claimants were in fact afraid of a particular Kazakh individual. In most situations of ethnic violence, however, pre-existing local disputes and power struggles (between individuals, families or groups) become drawn into the dynamics of violence; often, ethnic difference is utilized by particular community members as a justification for persecution, oppression or revenge.

Board Members also often seem incredulous at the arbitrary behaviour of the authorities (police, army, government) as recounted by claimants. The notion that terror and persecution are implemented precisely through arbitrariness, chaos and impunity seems difficult for them to grasp, and the inability of claimants to provide a rational reason for such abusive behaviour leads them to further doubt their story. In a case from Burma, for example, the Board Members found it contradictory that although the claimant's military persecutors 
covered her eyes when kidnapping her, they failed to do so again upon her release. They are unable to enter the 'illogical' atmosphere of terror and impunity, where uncontrolled military or police often commit human rights abuses without fear or precaution.

Simplistic representations of war and persecution lead some Board Members to assume that all 'normality' or daily life is altered or comes to a standstill in situations of violence. Clearly, however, the attempt to maintain one's sustenance, home, family and social relations is a survival mechanism for those caught in situations of turmoil, and most do not choose to leave until they have truly abandoned hope. In the Kazakh case, for example, the Board Members questioned how the family could have continued living within a certain margin of normality - that is, by continuing to operate their business and moving only when necessary - despite being targeted. Reasoning the other way, some Board Members question the credibility of claimants who are unable to maintain normal social relations under extreme conditions. In a case from Mexico, they seemed incredulous that the claimant's uncle 'deserted' his family after being targeted by the army, and that the 18-year-old claimant himself did not return home after being tortured to find out about his sisters. Here the notion that maintaining contact with family members, especially if one has been branded subversive, could endanger the entire family - particularly in places where army strategies are to attack families rather than individuals, and where the only option then is to 'disappear' - was not entertained by the Board Members.

Finally, in two cases, the Board Members were highly insensitive to the use of rape as a political weapon. They showed little empathy for claimants who stated that they were raped by authorities during detention, and rejected such claims due to the women's lack of evidence. In many cultures, however, rape results in a loss of honour for the woman and her family, who, as a consequence will not request documentation from a medical authority. In both of these cases, despite the claimants' clear trauma and shame, the Board Members were abrupt, dismissive and showed discomfort about the rape testimony.

The inability to fathom life in other cultures and situations, or even the plight of refugees in Canada, also creates false expectations of cultural coherence at a more general level, often reinforcing an atmosphere of suspicion and leading to the assumption of contradiction and non-credibility. Misinterpretations of other cultural norms are based, on the one hand, on assumptions of a universal Canadian cultural 'logic', and on the other on simplistic notions or stereotypes regarding other cultures. In a Mexican case, for example, a Board Member could not believe that a middle class family in Chiapas would not have a telephone, though this is not uncommon in the region. In a case from Cameroon, the Board Members were incredulous that a female claimant could at once work in her parents' business, care for her children and participate in political activities; as they stated in their written decision, 'a mother of five has no time for political involvement'. Their assessment of this woman's capacity for political work, which was one of the main reasons for rejecting her claim, 
was culturally misinformed and inappropriate, since in many cultures it is common for children to be raised by the extended family.

Board Members sometimes show an inability to appreciate cultural norms surrounding family relations and values in other cultures. In an Indian case, for example, the Board Members constantly questioned the behaviour of the claimant's father, in particular his calm attitude upon being told that his daughter was missing. As the claimant stated, her father was trying to maintain her reputation since her absence from home might have been interpreted as improper. The Members did not seem to understand, in this cultural context, how important it is for a father to protect his daughter's (and family's) reputation, and the strength of character required to hide one's emotions from strangers.

Cultural misunderstandings may also affect the ability to appreciate styles of narration, expression and emotion by cultural 'others', which in turn leads to erroneous interpretations of crucial elements of the claimant's testimony. In many cultures, a strong identification with a collective identity - whether based on family, lineage, clan, language group or a broader sense of ethnicity —often blurs the boundaries between individual and community. Descriptions of traumatic events are then narrated in the context of one's broader community or ethnic loyalties. This blurring of the 'I' and the 'we'-absent in a Western style of discourse which stresses the boundaries of individualism - reflects not only a cultural narrative style but also the manner in which many persecuted people experience and interpret the violence against them. In the Kazakh case, the commissioners interpreted this style as an attempt to conceal the 'personal' nature of the claimants' persecution. In addition, different cultures have varying codes regarding the contextual appropriateness and expression of emotions. In the context of IRB hearings, where claimants are recounting painful stories of trauma to strangers, the expression of emotions (by claimants) and the interpretation of emotional styles (by Board Members) are culture-specific and can be puzzling to both parties. For example, the strong public emotional reserve characterizing some groups (often those with a history of marginality or persecution) can lead claimants to downplay certain elements of their story or to choose answers which, to Western ears, may seem incomplete, elusive or lacking in credible detail.

Cultural misunderstandings can lead to frustration, impatience and sometimes subsequent aggression on the part of Board Members, who may then fail to listen properly to the testimony presented, dismiss information, and reject or distort the evidence provided by expert witnesses or lawyers. In several cases, this lack of cultural comprehension leads Board Members to demonstrate a profound insensitivity and lack of respect, compassion and objectivity toward the claimants, or to deflect hostility onto the lawyer, the expert witness or even the interpreter. Through such hostile projections, victims (i.e. claimants) are sometimes portrayed by the Board Members as aggressors or as deserving of the abuse they have received. In one case, for example, the claimant was implicitly associated with 'known war criminals' who have been able to obtain refugee status with the help of expert medical testimony, which was denounced 
as generally unreliable. And in several cases, this frustration leads Board Members to constantly interrupt the claimants' answers; as such, they shift rapidly from requiring detailed explanations to silencing the claimant who tries to provide them, leaving the latter perplexed and unable to know whether or not, and how, to answer.

Finally, lack of cultural understanding or receptivity often translates into suspicion and cynicism with respect to the testimonies presented. As a result of these misunderstandings, Board Members often perceive 'contradictions' where there are none, attempt to 'poke holes' in stories, and refuse to take into account the claimants' clarifications. As we have seen, the assumption of contradiction runs from minor details of the accounts to the broader political contexts of the stories, leads to unfounded assumptions and shifts in argument, and ultimately impacts on the overall assessment and prevents a fair or objective decision; indeed, smaller 'contradictions' are often generalized to a 'lack of credibility' regarding the whole story.

\section{Quantitative Findings}

The quantitative analysis of the 40 cases revealed that 20 per cent of the files present only one type of problem (juridical, cultural, or psychological), while 27.5 per cent show problems in two of the areas, and 52.5 per cent present problems in all three fields. This indicates an important overlap between the factors identified and may allow us to understand why purely legal and administrative efforts to improve the system might have failed to address the inherent problems.

At the legal level, the most prevalent problems concern the administration of evidence ( 87.5 per cent) and the social and political conditions of the country of origin (62.5 per cent). Problems in interpreting administrative and international law are also frequent (40 per cent). Finally, in more than a quarter of the cases (27.5 per cent), the rules of conduct and politeness were breached.

At the psychological level, we encounter problems of massive avoidance of traumatic content, which is a typical manifestation of vicarious traumatization (75 per cent), and lack of empathy ( 75 per cent). The expression of prejudice (67.5 per cent) and behaviour that denotes a certain cynicism (50 per cent) were also very prevalent. Finally, in more than a third of cases (35 per cent), it is possible to detect signs of emotional distress related to secondary trauma that is transferred to a number of different actors.

In the cultural field, lack of understanding of the refugee's cultural, social and political context of origin is a principal factor (72.5 per cent). Difficulty in properly assessing the social relations of the claimant is also important $(52.5$ per cent). Within the context of both the hearing and the decision, prejudices, stereotypes and difficulties in communicating play a role in 42.5 per cent of the files.

Denial was considered to be a problem by the coders in more than 90 per cent of the files. This phenomenon is partly due to the selection criteria: all the files had a negative decision that was based on non-credibility of the claimant. 
The results do not permit a clear distinction between psychological and cultural denial of reality in addition to ideological disagreements between the parties. As a rigorous, all-inclusive definition of denial was difficult to put into practice, we considered it best to omit it from the conclusions.

\section{Systemic Findings}

Even though the objective of our research was not of a systemic nature, we discovered and documented certain elements that, in addition to the characteristics of individual actors, appeared to have an important influence on the process.

The non-adversarial process seems to create much confusion as to the respective roles of the actors. The interventionist attitude of many Board Members often leads to a tense atmosphere including emotional reactions and, at times, aggressive behaviour by all actors. This has a very negative impact on the civility of the judicial debate, and adds to the confusion of many claimants who no longer know who they have to convince and against whom they have to defend themselves. As there is no 'official adversary', the lawyer often does not know what attitude to take toward the Board Members, who often present themselves as protective of refugees while simultaneously adopting aggressive attitudes towards the claimants. If the lawyer tries a conciliatory approach, he runs the risk of appearing unconvincing or of approving unacceptable demands, such as the stripping of the little boy's torso to show the scars. If he tries an aggressive approach, he risks antagonizing the Board Members. Depending on the Board Members' attitude in the case, the RCOs are often cautious, asking general questions, drawing unhelpful conclusions: in one case, the RCO simply concluded that the Board Members would have to determine whether the claimant was credible. At other times, especially when the Board Members do not intervene much, the RCO acts as a public prosecutor, crossexamining the claimant on each and every detail that could point to a 'contradiction'. In many cases, the RCO is the person most ill at ease in the system: it might be advisable to rethink their role, whatever other solutions may be adopted. The interpreters may also be affected by the unacknowledged interpersonal conflicts between the actors, and have a tendency to side, for emotional reasons, with one or other of the actors, which might show in their attitudes.

The general climate of tension is either concretized in direct conflicts, or displaced against one of the other actors. All this confusion results in much uneasiness in the way the actors interact. Not only is there a confusion in the legal role of each actor, but this confusion has a tremendous impact on the psychological and cultural dimensions, which as seen above already reinforce the general sense of uncertainty.

\section{Discussion}

Our results suggest a wide overlap among legal, psychological and cultural factors which appear problematic in the IRB decision-making process. The 
majority of cases not only present problems in more than one domain, but the meanings of specific events vary in these domains in a complex way. For example, breaking the rules of politeness in a hearing is a legal error and can have catastrophic consequences psychologically if the frightened claimant becomes increasingly confused. In the same way, the lack of contextual and cultural understanding or sensitivity often leads the Board Members or RCO to focus on insignificant details, which elicits rejection feelings in the claimant and leads to very poor administration of the evidence in the decision.

This interlocking of different domains becomes further complicated by institutional and systemic issues. The double bind in which the non-adversarial process places the claimant, from the explicit discourse 'we are here to protect you' to the implied construing of the refugee as a liar, if not a criminal, is structured, on the one hand, around societal representations of the refugee and of the 'pure' victim, and, on the other, around political and public opinion pressure to align Canada's rates of acceptance of refugees with those of most other Western countries. Indeed, our data suggest that there exists a 'culture of disbelief' within the structure of the IRB; however, given our restricted sample and methodology, such a claim would require further research.

Taken one by one, the legal, cultural and psychological aspects of the workings of the IRB Members are not sufficient, on their own, for us to call into question the decision-making process. Each of these aspects can be used in isolation to make particular decisions appear well-founded. However, the convergence of the political dimensions to a case (and any lack of understanding thereof), the unspoken personal processes at work, the social representations of each actor and the emotional burden of the hearing on the decision-makers, makes their task difficult, and causes analysts, such as the authors of this article, to have difficulty in finding solutions to this problem.

Our results suggest possible avenues to increase the capacities of the Board Members to fulfil their roles. Board Members should be selected, and should be known to be selected, according to their abilities and experience. These abilities and experience should cover three areas:

- Legal knowledge: refugee law, immigration law, human rights law, conduct of judicial hearings, how to interact with counsels and claimants, how to assess the evidence, how to write decisions; etc.

- Experience in the field: work in countries torn by war or internal strife; work with refugees or displaced persons; sensitivity to the dynamics involved in working with people from other cultures, in terms of communication and understanding; etc.

- Psychological abilities: capacity to bear the suffering of all actors, including themselves; experience in dealing with traumatized persons; etc.

It is unrealistic to expect each Board Member to be excellent in all three areas, but it would be important for candidates to show experience and skills in all three, with some degree of excellence in one or two. Only then would they be confident enough and command enough respect to use the position of authority 
that they hold in order to impose standards of quality on the behaviour of all other actors.

The training of all actors must be improved. A continuing and well-designed training programme oriented towards cultural and psychological sensitivity as well as a basic social science framework concerning issues of war, poverty and the refugee process should be offered to all actors. This training should avoid being just a check-list of the basic 'differences' of other cultural norms, modes of communication, psychological reactions to trauma and various political upheavals throughout the world. Rather, it would propose a broader discussion concerning 1) the construction, perception and experience of cultural difference; 2) the complexities and nuances of situations of political violence, low-intensity conflict, ethnic strife, illiteracy, rural culture, etc.; 3) the refugee experience; 4) the diversity of responses to trauma and their influence on the hearing.

The limitations of this pilot project should be borne in mind when interpreting the results presented here. These include: the local character of the cases examined, the lack of estimation of inter-rater agreement between coders, the paucity of data on Board Members' backgrounds, as well as the small sample involved. These limitations signal a need for caution with regard to the possibility of generalizing the results, and suggest the need for further studies. Subsequent research should ideally be conducted in various sites, and should complement the qualitative perspective by using an epidemiological approach that would highlight the prevalence of the problems detected. The participation of the IRB in the conceptualization and implementation of such a research project would be highly valuable.

However, taking into account these limitations, our results suggest that in order to understand and resolve the problems faced by the IRB, a radically different approach is needed. On the one hand, this study confirms empirical knowledge from refugee advocacy groups and refugee studies scholars on the inadequacies within the system. Research data can strengthen this position, often dismissed as mainly ideological, and fuel the fight to improve the system at the supranational level, pressuring States on the basis of their international image. On the other hand, the complexity of the dynamic observed points to the fact that an administrative tribunal like the IRB cannot be transformed without an internal realization that work is needed; and that, even if this internal realization is triggered by external pressure, it should rely on partnership, negotiation and building a certain level of trust among all concerned. Modifying the administrative parameters without addressing the underlying representations will probably just replicate the multiple unsuccessful attempts to transform the system. A multidisciplinary perspective is essential to understanding both the personal and systemic factors that appear to be problematic in the refugee determination process. The gaps or deficiencies identified here demonstrate that the integration of legal, cultural and psychological dimensions should not only inform future research, but should also be reflected in the selection and training of the various actors. The Board Members, the RCOs and the other professionals involved have a heavy responsibility to guarantee 
the right of asylum and the protection of refugees. Only a critical vision that encourages a creative role for each actor in the system as a whole can help fulfil this mandate.

1. Biographical information on the latest appointees may be found on the website of Citizenship and Immigration Canada, at: www.cic.gc.ca, under 'What's new?'

2. Crépeau, F. and Houle, F., 'Compétence et indépendance: Clefs de la crédibilité de tout processus de reconnaissance du statut de réfugié', Mémoire déposé auprès de la Ministre de la Citoyenneté et de l'Immigration lors des consultations sur le Rapport Trempe-Davis-Kunin, 6 March 1998, 32 pp. A more recent version of the same, adapted to Bill C-31 that was studied by Parliament between March and October 2000 (though never adopted) and C-11 (essentially identical to C-31) which was tabled in the House on 21 February 2001, can be found under the citation: Crépeau, F. and Houle, F., 'La sécurité des réfugiés et la compétence des commissaires de la CISR: les silences inopportuns du projet de loi C-11'/'The Security of Refugees and the Abilities of IRB Members: the Inappropriate Silence of Bill C-11', 12 March 2001. It can be found at: http://www.juris.uqam.ca/cedim/indexfr.html_ Recherches.

AIGNER, U. M. (1995) Intercultural Communication: Considerations and Limitations as Reflected in Translation, with Practical Applications for Canadian Refugee Claimants. Montreal: Communications, McGill University.

ATLANI, L. and ROUSSEAU, C. (2000) 'The Politics of Culture in Humanitarian Aid to Refugees having Experienced Sexual Violence', Transcultural Psychiatry 37(3): 435-465.

BARSKY, R. F. (1994) Constructing a Productive Other: Discourse Theory and the Convention Refugee Hearing. Amsterdam/Philadelphia: John Benjamins Publishing Company.

- (2000) Arguing and Justifying: Assessing the Convention Refugees' Choice of Moment, Motive and Host Country. Aldershot: Ashgate.

BEISER, M. (1993) 'After the Door has been Opened: The Mental Health of Immigrants and Refugees in Canada', in V. Robinson (ed.), The International Refugee Crisis: British and Canadian Responses. London: Macmillan, p. 213-227.

DANIEL, E. V. and KNUDSEN, J. C. (1995) Mistrusting Refugees. Berkeley: University of California Press.

DANIELI, Y. (1998) International Handbook of Multigenerational Legacies of Trauma. New York: Plenum Press.

FORNAZZARI, X. (1995) 'The Trauma of Exile and Resettlement', in K. Price (ed.), Community Support for Survivors of Torture: A Manual. Toronto: Canadian Centre for Victims of Torture, pp. 14-22.

GEERTZ, C. (1973) The Interpretation of Cultures: Selected Essays. New York: Basic Books.

GOFFMAN, I. (1969) Social Interaction. Chicago: University of Chicago Press.

HATHAWAY, J. C. (1993) Rebuilding Trust: Report of the Review of Fundamental Justice in Information Gathering and Dissemination at the Immigration and Refugee Board of Canada, Ottawa.

JARANSON, J. M. (1995) 'Government Sanctioned Torture: Status of the Rehabilitation Movement', Transcultural Psychiatric Research Review 32: 253-286.

KÄLIN, W. (1986) 'Troubled Communication: Cross-Cultural Misunderstandings in the Asylum Hearing', International Migration Review 2(2): 230-241.

KIRMAYER, L. J. (1996) 'Landscapes of Memory: Trauma, Narrative, and Dissociation', in P. A. M. Lambek (ed.), Tense Past: Cultural Essays in Trauma and Memory. New York: Routledge, pp. 173-198.

KNAPP, K., ENNINGER, W. and KNAPP-POTTHOFF, A. (1987) Analysing Intercultural Communication. Berlin: Mouton de Gruyter.

LEVY, V., DONGIER, P., LILLO, C., HÉBERT, D. and CÔTÉ, M.-L. (1998) Personne ayant subi la violence organisée. L'évaluation psychologique et médicale dans le processus de revendication du statut de réfugié. Réseau canadien pour la santé des victimes de la torture et de la violence organisée (RIVO), Montreal, pp. 18. 
LOESCHER, G. (1993) Beyond Charity: International Cooperation and the Global Refugee Problem. New York/Oxford: Oxford University Press.

MALKKI, L. (1992) 'National Geographic: The Rooting of Peoples and the Territorialization of National Identity among Scholars and Refugees', Cultural Anthropology 7(1): 24-44.

MOELLER, S. and CHRISTIANSEN, L. K. (1996) 'How Dealing with Traumatized Refugees Affects the Therapist and the Institution Concerned', in K. Pelzer (ed.) Counselling and Psychotherapy of Victims of Organised Violence in Sociocultural Context. Frankfurt: IKOVerlag für Interkulturelle Kommunikation, pp. 240-243.

PELOSI, A. M. (1996) Intercultural Communication in the Refugee Determination Hearing. Montreal: School of Social Work, McGill University.

PELTZER, K. (1997) 'Counselling and Rehabilitation of Victims of Human Rights Violations in Africa', Psychopathologie africaine 28(1): 55-87.

PYNOOS, R. S. and NADER, K. (1989) 'Case Study: Children's Memory and Proximity to Violence', Journal of American Academy of Child and Adolescent Psychiatry 28(2): 236-241.

ROUSSEAU, C. (1998) 'Familial History of War Trauma in Refugee Adolescents: A Longitudinal Study', in D. I. Hassall (ed.), Protecting Children: Innovation and Inspiration - Te Hui Taumata monga Tamariki '98. Auckland, New Zealand: International Society for Prevention of Child Abuse and Neglect (ISPCAN), pp. 15-16.

- (2000) 'Les réfugiés à notre porte: violence organisée et souffrance sociale', Criminologie 33(1): $185-201$.

SAMOVAR, L. and PORTER, R. (1994) Intercultural Communication: A Reader. Belmont, CA: Wadsworth.

SHOWLER, P. (2000) Oral statement at the Spring meeting of the Canadian Council for Refugees, Vancouver, June.

SILK, J. (1986) Despite a Generous Spirit: Denying Asylum in the United States. Washington: United States for Refugees.

SILOVE, D., STEEL, Z. and WATTERS, C. (2000) 'Policies of Deterrence and the Mental Health of Asylum Seekers', Journal of the American Medical Association 284(5): 604-611.

TERR, L. (1983) 'Time Sense Following Psychic Trauma: A Clinical Study of Ten Adults and Twenty Children', American Journal of Orthopsychiatry 54: 244-262.

UNHCR (1992) Handbook on Procedures and Criteria for Determining Refugee Status. Geneva: UNHCR.

VINAR, M. and VINAR, M. (1989) Exil et torture. Paris: Éditions Denoël.

WATSON, S. (1995) 'Preparing Caregivers to Work with Survivors of Torture: The Importance of Self-awareness and Self-care', in K. Price (ed.), Community Support for Survivors of Torture: A Manual. Toronto: Canadian Centre for Victims of Torture, pp. 111-119.

ZOLBERG, A. R., SUHRKE, A. and AGUAYO, S. (1989) Escape from Violence: Conflict and the Refugee Crisis in the Developing World. Oxford: Oxford University Press.

\section{Reported Cases}

Adjei v. Canada (Minister of Employment and Immigration), (1989) 7 Imm. L.R. 169 at 173 (F.C.A.). Alfred v. Canada (Minister of Employment and Immigration), (1994) 76 FTR 231.

Bouguettaya v. Canada (Minister of Citizenship and Immigration), [2000] A.C.F. no 992 (j. Lemieux). Chan v. Canada (Minister of Employment and Immigration), [1995] 3 S.C.R. 593 (S.C.C.).

Gengeswaran v. Canada (Minister of Citizenship and Immigration), (May 19, 1999), Doc. IMM4318-98 (FTD).

Gracielome v. Canada (Minister of Employment and Immigration), (1989) 9 Imm. L.R. (2d) 237 (FCA).

Leung v. Canada (Minister of Employment and Immigration), (1994) 81 FTR 303.

Magana v. Canada (Minister of Citizenship and Immigration), (May 8, 1996), Doc. IMM-1608-95 (FTD).

Menaker v. Canada (Minister of Citizenship and Immigration), (Oct. 27, 1997), Doc. Imm-3837-96 (FTD).

Njoko v. Canada (Minister of Employment and Immigration), (January 25, 1995), Doc. A-1698-92 (FTD).

Otoo v. Canada (Minister of Citizenship and Immigration), (February 9, 1996), Doc. IMM-5056 (FTD). 


\section{C. Rousseau, F. Crépeau, P. Foxen, F. Houle}

Owusu-Ansah v. Canada (Minister of Employment and Immgration) (1989) 8 Imm. L.R. (2d) 106 (FCA).

Parizi v. Canada (Minister of Citizenship and Immigration), (1994) 90 FTR 189.

Singh v. Canada (Minister of Employment and Immigration) [1985] 1 S.C.R. 177.

Sivayoganathan v. Canada (Minister of Citizenship and Immigration), (1994) 86 FTR 152.

Vidhani v. Canada (Minister of Citizenship and Immigration), [1995] 3 F.C. 60.

Yusuf v. Canada (Minister of Employment and Immigration), (October 24, 1991) A-1116-90 (F.C.A.).

Zapata v. Canada (Solicitor General), (1994) 82 FTR 34 (FTD).

MS received May 2001; revised MS received February 2002 